\title{
ALGORITMA FUZZY NAIVE BAYES UNTUK MENGKLASIFIKASIKAN BIDANG KEAHLIAN MAHASISWA TEKNIK INFORMATIKA UNIVERSITAS ISLAM LAMONGAN
}

\author{
Nurul Fuad \\ Program Studi Teknik Informatika, Universitas Islam Lamongan \\ Email:nurulfuad2@gmail.com
}

\begin{abstract}
ABSTRAK
Pemilihan jurusan pada jenjang universitas sangat menentukan akan output yang dihasilkan, artinya jika mahasiswa dalam menentukan pilihan jurusan sesuai dengan bidang keahliannya maka dipastikan tidak akan ada kesulitan untuk mengembangkan diri dalam proses perkuliahan.Dalam penelitian ini menggunakan dua algoritma, yaitu Fuzzy dan Naive Bayes untuk mengklasifikasi bidang keahlian mahasiswa. Mahasiswa dalam perkuliahan mempunyai hoby dan kesukaan yang berbeda-beda terhadap mata kuliah. Mahasiswa Teknik Informatika mempunyai kesempatan dalam memilih bidang keahlian, yaitu: bidang keahlian jaringan, pemrograman, dan desain. Mahasiswa tidak semua akan menguasai bidang keahlian tersebut, sehingga harus memilih sesuai skill, hoby dan mata kuliah kesukaan, dan nilai. Penelitian ini akan membuat system untuk mengklasifikasi bidang keahlian mahasiswa teknik informatika UNISLA. Algoritma yang diimplimentasikan, yaitu Fuzzy untuk mengkategorikan dari nilai atau inputan angka, sedangkan naïve bayes digunakan untuk klasifikasi, dalam uji coba sistem ini didapatkan akurasi $100 \%$ dengan errored $0 \%$ dari 243 data yang olah pada proses training.
\end{abstract}

Kata Kunci: Naive Bayes, Fuzzy,Bidang Keahlian

\begin{abstract}
The selection of majors at the university level will determine the output produced, meaning that if students determine the choice of majors in accordance with their field of expertise, then certainly there will be no difficulty to develop themselves in the lecture process. In this study using two algorithms, namely Fuzzy and Naive Bayes to classify area of expertise of students. Students in lectures have different hobbies and preferences for the course. Informatics Engineering students have the opportunity to choose a field of expertise, namely: the field of network expertise, programming, and design. Not all students will master the area of expertise, so they must choose according to their skills, hobbies and favorite subjects, and grades. This research will create a system for classifying the expertise of UNISLA informatics engineering students. The algorithm is implemented, namely Fuzzy to categorize the values or input numbers, while naïve bayes are used for classification, in testing this system obtained 100\% accuracy with errored $0 \%$ from 243 data processed in the training process.
\end{abstract}

Keywords: Naive Bayes, Fuzzy, Field of Expertise

\section{PENDAHULUAN}

Perguruan tinggi merupakan salah satu lembaga pendidikan yang penting untuk mendidik, mencetak dan membekali sumber daya manusia supaya menjadi tenaga profesional. Pada tingkat perguruan tinggi seseorang belajar sesuai bidang keahlian tertentu, sehingga output dari sebuah perguruan tinggi diharapakan mampu menghasilkan sumber daya manusia yang berkualitas sesuai dengan bidang keahlian mahasiswa masingmasing berdasarkan bidang minat yang telah di pilih.oleh sebab itu pengelompokkan mahasiswa berdasarkan minat bidang keahlian sangat dibutuhkan di fakultas guna mendukung dan mempermudah kebijakan yang dikeluarkan oleh fakultas untuk mendapatkan outputan sumber daya manusia yang sesuai kebutuhan masyarakat umum.

Bidang keahlian merupakan bagian dari kurikulum berbasis kopetensi. Bidang keahlian adalah kumpulan dari beberapa matakuliah pendukung yang akan mengantarkan Mahasiswa menuju proses penyelesaian skripsi. Adapun bidang peminatan yang ada pada program studi Teknik Informatika Unisla adalah Jaringan, Pemograman dan Desain.Mahasiswa harus mampu menjadi tenaga yang professional. Sehingga perlu disesuaikan dengan bidang keahlian, untuk 
menentukan bidang keahlian tersebut dapat diambil dari beberapa variabel diantaranya skill kesukaan mata kuliah, hoby dan IPK agar dapat memilih bidang sesuai dengan keahlian karena tidak jarang juga mahasiswa dalam menentukan bidang minat secara asal - asalan yang mereka minati tidak berdasarkan kreteria yang telah dianjurkan oleh jurusan Universitas Islam Lamongan.seiring dengan perkembangan teknologi permasalahan tersebut dapat diantisipasi dengan cara klasifikasi atau pengelompokan bidang minat sesuai dengan kreteria yang telah ditentukan.

Dari permasalahan di atas, maka akan dibangun system untuk mengklasifikasikan atau menenukan bidang keahlian mahasiswa berdasarkan hoby, skill, mata kuliah favorit, IPK dengan algoritma Fuzzy Naïve Bayes. Data inputan angka (IPK) dilakukan konversi ke bentuk kategori menggunakan algoritma Fuzzy sedangkan untuk menentukan bidang keahlian mahasiswa menggunakan algoritma Naïve Bayes.

\section{TINJAUAN PUSTAKA}

\subsection{Himpunan Fuzzy}

Berikut gambaran himpunan fuzzy,Pada himpunan tegas (crisp), nilai keanggotaan suatu item $\mathrm{x}$ dalam suatu himpunan $\mathrm{A}$, yang sering ditulis dengan $\mu_{\mathrm{A}}[\mathrm{x}]$, memiliki 2 kemungkinan, yaitu:

1. satu (1), yang berarti bahwa suatu item menjadi anggota dalam suatu himpunan, atau

2. nol (0), yang berarti bahwa suatu item tidak menjadi anggota dalam suatu himpunan.

Himpunan fuzzy memiliki 2 atribut, yaitu:

1. Linguistik, yaitu penamaan suatu grup yang mewakili suatukeadaan atau kondisi tertentu dengan menggunakan bahasa alami.

2. Numeris, yaitu suatu nilai (angka) yang menunjukkan ukurandari suatu variable.

Ada beberapa hal yang perlu diketahui dalam memahami sistem fuzzy, yaitu:

1. Variabel Fuzzy

Variabel fuzzy merupakan variabel yang hendak dibahas dalam suatu sistem Fuzzy.

2. Himpunan Fuzzy

Himpunan fuzzy merupakan suatu grup yang mewakili suatu kondisi atau keadaan tertentu dalam suatu variabel Fuzzy.

Contoh: Variabel temperatur, terbagi menjadi 5 himpunan Fuzzy, yaitu: Dingin, Sejuk, Normal, Hangat, dan Panas.

\subsubsection{Fungsi Keanggotaan}

Fungsi Keanggotaan (membership function) adalah suatu kurva yang menunjukkan pemetaan titik-titik input data ke dalam nilai keanggotaannya (sering juga disebut dengan derajat keanggotaan) yang memiliki interval antara 0 sampai 1 . Salah satu cara yang dapat digunakan untuk mendapatkan nilai keanggotaan adalah dengan melalui pendekatan fungsi. Ada beberapa fungsi yang bisa digunakan.

\subsubsection{Penalaran Monoton}

Metode penalaran secara monoton digunakan sebagai dasar untuk teknik implikasi fuzzy. Meskipun penalaran ini sudah jarang sekali digunakan, namun terkadang masih digunakan untuk penskalaan fuzzy. Jika 2 daerah fuzzy direlasikan dengan implikasi sederhana sebagai beriku

$$
\begin{aligned}
& \text { IF } x \text { is } A \text { THEN } y \text { is } B \\
& \text { transfer fungsi: } \\
& y=f((x, A), B)
\end{aligned}
$$

maka sistem fuzzy dapat berjalan tanpa harus melalui komposisi dan dekomposisi fuzzy. Nilai output dapat diestimasi secara langsung dari nilai keanggotaan yang berhubungan dengan antesedennya.

\section{Contoh 2.1}

Misalkan ada 2 himpunan fuzzy: TINGGI (menunjukkan tinggi badan orang Indonesia) dan BERAT (menunjukkan berat badan orang Indonesia) seperti terlihat pada Gambar 2.3

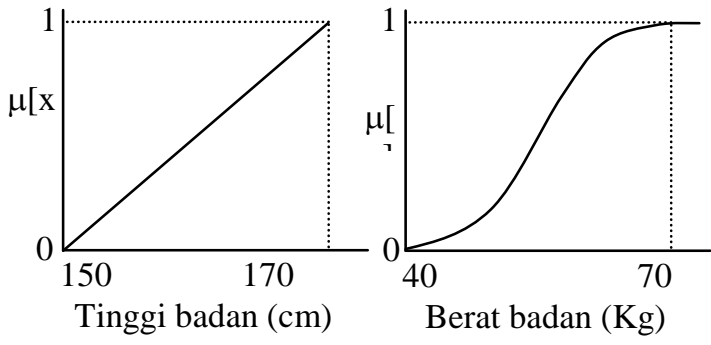

Gambar 2.3 Himpunan fuzzy: TINGGI dan BERAT.

Hubungan antara kedua himpunan diekspresikan dengan aturan tunggal sebagai berikut:

$$
\text { IF TinggiBadan is TINGGI }
$$

THEN BeratBadan is BERAT

Implikasi secara monoton akan menyeleksi daerah fuzzy A dan B dengan algoritma sebagai berikut:

- Untuk suatu elemen x pada domain A, tentukan nilai keanggotannya dalam daerah fuzzy A, yaitu: $\mu_{\mathrm{A}}[\mathrm{x}]$;

- Pada daerah fuzzy B, nilai keanggotaan yang berhubungan dengan tentukan 
permukaan fuzzy-nya. Tarik garis lurus ke arah domain. Nilai pada sumbu domain, y, merupakan solusi dari fungsi implikasi tersebut. Dapat dituliskan:

$$
\mathrm{y}_{\mathrm{B}}=f\left(\mu_{\mathrm{A}}[\mathrm{x}], \mathrm{D}_{\mathrm{B}}\right)
$$

Gambar 7.29 menunjukkan kerja algoritma tersebut. Seseorang yang memiliki tinggi badan $165 \mathrm{~cm}$, memiliki derajat keanggotaan 0,75 pada daerah fuzzy TINGGI; diperoleh dari:

$$
\begin{aligned}
\mu_{\text {TINGGI }}[165] & =(165-150) /(170-150) \\
& =15 / 20 \\
& =0,75
\end{aligned}
$$

Nilai ini dipetakan ke daerah fuzzy BERAT yang akan memberikan solusi berat badan orang tersebut yaitu $59,4 \mathrm{~kg}$; diperoleh dari:

$$
\mu_{\text {BERAT }}[\mathrm{y}] \quad=\mathrm{S}(\mathrm{y} ; 40,55,70)=0,75
$$

Karena 0,75 > 0,5 maka letak y adalah antara 52,5 sampai 70,sehingga:

$$
\begin{array}{ll}
\Leftrightarrow 1-2[(70-y) /(70-40)]^{2} & =0,75 \\
\Leftrightarrow 1-2(70-y)^{2} / 900 & =0,75 \\
\Leftrightarrow 2(70-y)^{2} / 900 & =0,25 \\
\Leftrightarrow(70-y)^{2} & =112,5 \\
\Leftrightarrow(70-y) & = \pm \sqrt{ }(112,5) \\
\Leftrightarrow y & =70 \pm 10,6 \\
--->\text { mbil }(-) \text { nya, karenanilainya harus }< \\
70 & \\
\Leftrightarrow y & =59,4
\end{array}
$$
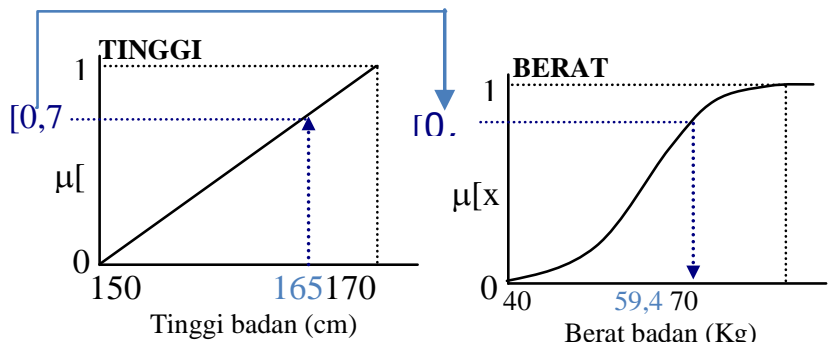

Gambar 1.1

\subsubsection{Fungsi Implikasi}

Tiap-tiap aturan (proposisi) pada basis pengetahuan fuzzy akan berhubungan dengan suatu relasi fuzzy.Bentuk umum dari aturan yang digunakan dalam fungsi implikasi adalah:

IF $x$ is $A$ THEN $y$ is $B$

dengan $\mathrm{x}$ dan $\mathrm{y}$ adalah skalar, dan $\mathrm{A}$ dan $\mathrm{B}$ adalah himpunan fuzzy. Proposisi yang mengikuti IF disebut sebagi anteseden, sedangkan proposisi yang mengikuti THEN disebut sebagai konsekuen. Proposisi ini dapat diperluas dengan menggunakan operator fuzzy, seperti:

$$
\begin{aligned}
& \operatorname{IF}\left(x_{1} \text { is } A_{1}\right) \bullet\left(x_{2} \text { is } A_{2}\right) \bullet\left(x_{3}\right. \\
& \text { is } \left.A_{3}\right) \bullet \ldots \ldots \cdot\left(x_{N} \text { is } A_{N}\right) \text { THEN } y \\
& \text { is } B
\end{aligned}
$$

dengan - adalah operator (misal: OR atau AND).

Secara umum, ada 2 fungsi implikasi yang dapat digunakan, yaitu:

a. Min (minimum). Fungsi ini akan memotong output himpunan fuzzy. Gambar 2.9 menunjukkan salah satu contoh penggunaan fungsi min.
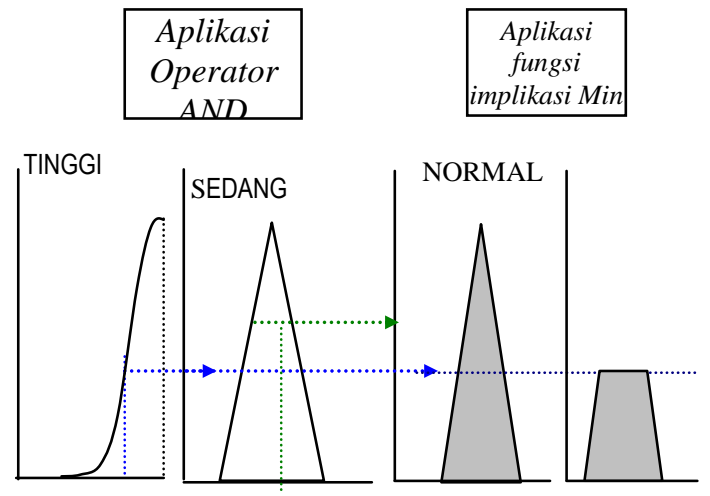

IF Permintaan TINGGI AND BiayaProduksi SEDANG THEN ProduksiBarang NORMAL

\subsection{Naive Bayes}

Algoritma Naive Bayes merupakan salah satu algoritma yang terdapat pada teknik klasifikasi.Naive Bayes merupakan pengklasifikasian dengan metode probabilitas dan statistik yang dikemukan oleh ilmuwan Inggris Thomas Bayes, yaitu memprediksi peluang di masa depan berdasarkan pengalaman dimasa sebelumnya sehingga dikenal sebagai Teorema Bayes. Teorema tersebut dikombinasikan dengan Naive dimana diasumsikan kondisi antar atribut saling bebas. Klasifikasi Naive Bayes diasumsikan bahwa ada atau tidak ciri tertentu dari sebuah kelas tidak ada hubungannya dengan ciri dari kelas lainnya. Persamaan dari teorema Bayes adalah $\therefore$

$$
P(H \mid E)=\begin{gathered}
P(E \mid H) * P(H) \\
P(E)
\end{gathered}
$$

Keterangan :

$\mathrm{X}$ : Data dengan class yang belum diketahui $\mathrm{H}$ : Hipotesis data $\mathrm{X}$ merupakan suatu class spesifik

$\mathrm{P}(\mathrm{H} \mid \mathrm{X})$ : Probabilitas hipotesis $\mathrm{H}$ berdasar kondisi $\mathrm{X}$ (posterioriprobability)

$\mathrm{P}(\mathrm{H})$ : Probabilitas hipotesis $\mathrm{H}$ (prior probability)

$\mathrm{P}(\mathrm{X} \mid \mathrm{H})$ : Probabilitas $\mathrm{X}$ berdasarkan kondisi pada hipotesis $\mathrm{H}$

$\mathrm{P}(\mathrm{X})$ : Probabilitas X

Dalam penelitian Nur Nafi'iyah, Siti Mujilahwati, 2018 menyebutkan bahwa algoritma Naïve Bayes dapat digunakan dalam proses identifikasi jenis kelamin manusia 
dengan nilai akurasi $80 \%$, dan inputan dataset dari naïve bayes lebih baik dalam bentuk kategori.

Penelitian lainya dalam klasifikasi, yaitu penelitian Nur Nafi'iyah, Chastine Fatichah, 2018 algoritma ID3 dataset inputan lebih baik dibuat dalam bentuk kategori, sehingga algoritma fuzzy digunakan sebagai cara mengkonversi inputan angka ke kategori.

Penelitian Darmawan, 2017 proses penentuan dosen pembimbing seminar proposal menggunakan data 100 mahasiswa yang berbeda judul beserta dosen pembimbing. Dari data lama tersebut digunakan untuk menentukan mahasiswa baru yang akan mengajukan proposal skripsi menggunakan algoritma naïve bayes.

Algoritma Naïve Bayes harus menggunakan dataset terlebih dahulu sebagai sumber belajar dalam menentukan keputusan. Dataset dari algoritma Naïve Bayes lebih baik dalam bentuk kategori, agar dapat mengubah bentuk kategori diterapkan algoritma Fuzzy. Di mana Fuzzy terlebih dahulu diset himpunan keanggotaannya, selanjutnya dilakukan tahap inferensi menggunakan rule, dan dihasilkannya value kategori.

\section{PERANCANGAN SISTEM}

Proses pertama yang dilakukan adalah mengumpulkan data informasi mahasiswa semester 5 dan 7 melalui quisioner online kemudian melakukan preprocessing dengan cara melakukan penapisan data untuk selanjutnya disimpan pada databse yang nantinya dijadikan data traning dan testing pada uji coba sbidang minat,sistem pemilihan bidang keahlian ini berdasakan skill, hoby dan mata kuliah kesukaan, dan nilai. Agar dapat membantu mahasiswa dalam memilih bidang keahlian, maka peneliti akan membuat system untuk mengklasifikasi bidang keahlian mahasiswa teknik informatika UNISLA. Algoritma yang digunakan, yaitu Fuzzy untuk mengkategorikan dari nilai atau inputan angka, sedangkan naïve bayes digunakan untuk klasifikasi

\subsection{Proses Konversi IPK Menggunakan Fuzzy}

1. Inputan sistem ada data masasiswa semester 5 \& 7

2. Pre processing ini adalah menyiapkan data dan mealkukan filtering pada data yang kurang layak

3. proses traning adalah..pembelajaran pada sistem yang nantinya ada testing

4. pada bagian ini ada proses konversi angka ke bentuk kategori (Rendah, sedang, tinggi) menggunakan fuzzy

5. pada bagian ini Proses Uji coba system untuk menentukan bidang keahlian mahasiswa dengan menggunakan algoritma Naïve Bayes

6. kemudian proses yang terakhir melakukan analisa mengenai hasil dari sistem

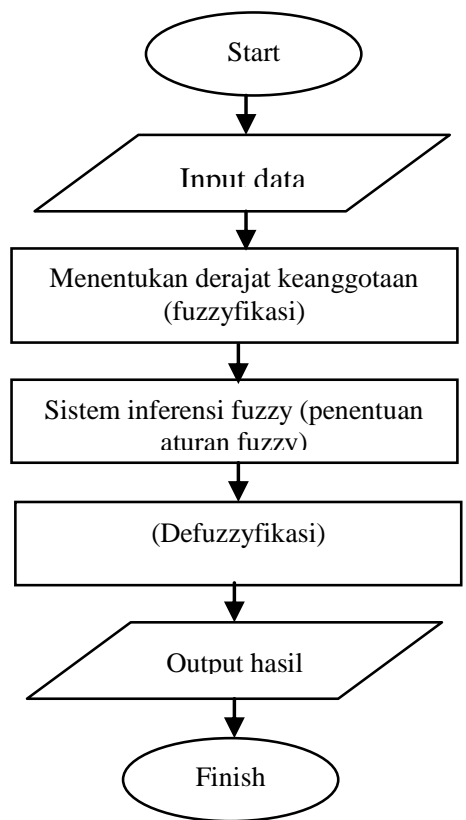

\section{Gambar 3.1 Alur Konversi IPK dengan Fuzzy}

3.2 Proses Pemilihan Jurusan Menggunakan Naive Bayes a. Proses Training

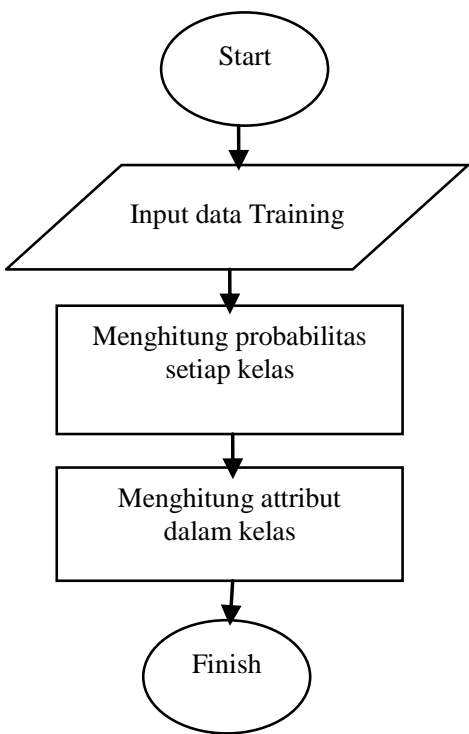

Gambar 3.2 Pemilihan Jurusan Dengan Naive Bayes 
Pada proses training ini data mahasiswa yang telah melalui preprosesing dan pengolahan fuzzy akan di masukkan data base kemudian dilakukan penghitungan probabilitas menggunakan naive bayes selanjutnya menentukan kelas berdasarkan hasil perhitungan

\section{b. Proses Testing}

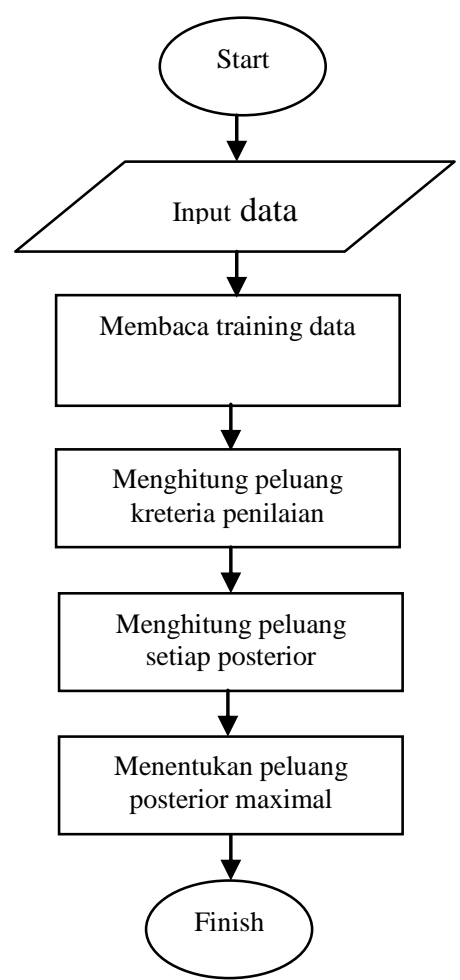

Gb. 3.3 Proses Testing

Pada proses data testing data dimputkan atau diload dari database kemudian dilakukan pembelajaran dari data traning dan selanjutnya dilakukan perhitungan peluang berdasarkan kreteria secara sistem dan terakhir menghitung peluang posterior dan hasil.

\section{Implementasi dan Pembahasan 4.1 Data Inputan}

Dari data pada Tabel 4.1 kemudian diolah dengan cara dilakukan preprocessing, prosesnya yaitu menghilangkan data yang kurang lengkap dalam mengisi quesioner, menghapus data ganda dan di simpan dengan format *.CSV. Data tersebut selanjutnya dijadikan untuk data latih atau training pada proses klasifikasi pemilihan bidang minat.

Berikut contoh data inputan yang akan diolah untuk dilakukan klasifikasi seperti Tabel 4.1:

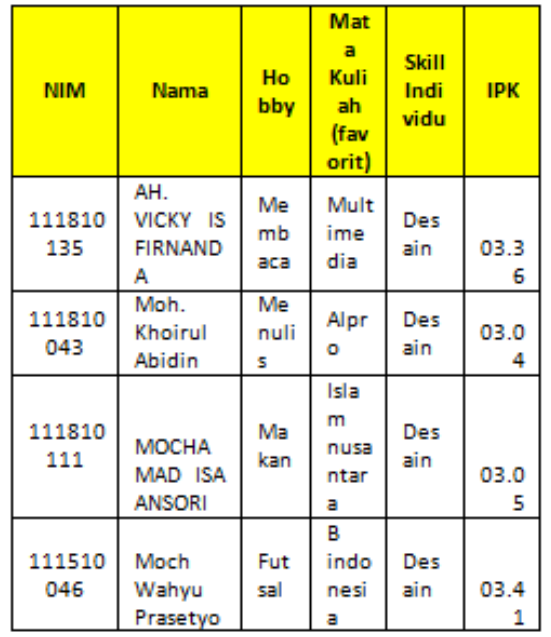

Table 4.1 contoh data inputan

\subsection{Menu Utama Program}

Berikut gambar 4.1 menu utama program, yang berisi menu pilihan training testing dan prediksi

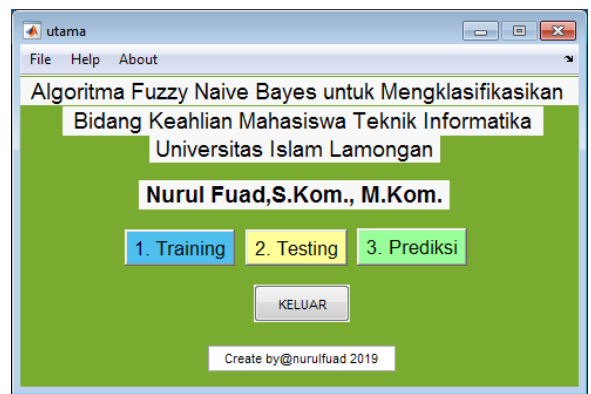

Gambar 4.1 Menu Utama

Pada menu training gunakan untuk melakukan pelatihan data yang akan di uji, menu testing digunakan untuk melakukan testing pada data yang telah dilatih sedangkan menu prediksi digunakan untuk melakukan prediksi pada data asli inputan yang belum dilakukan training.

\subsection{Menu Training}

Pada Gambar 4.2 berikut ini adalah menu training yang digunakan untuk melakukan proses pelatihan data sebelum dilakukan uji coba atau testing

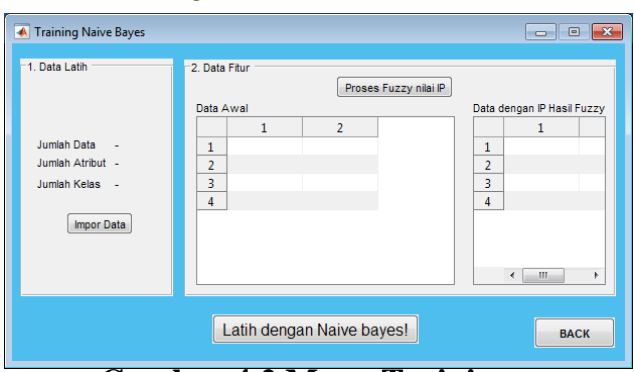

Gambar 4.2 Menu Training 
Untuk prosesnya data diload atau diimpor kemudian ditampung didalam table kemudian disimpan dalam file .*CSV.mat.berikut hasil dari import data

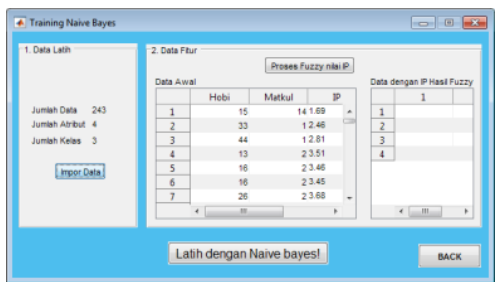

Gambar 4.3 Hasil import Data

Didalam proses training ini terdapat dua pengolahan data, yang pertama pengolahan IPK menggunakan algoritma fuzzy sedangkan untuk klasifikasi menggunakan algoritma naive bayes, adapun segmen program pada proses fuzzy tersebut seperti pada segment 4.1 hasil untuk proses pengolahan IPK menggunkan fuzzy seperti gambar 4.4 berikut ini:

\section{Segmen 4.1 Program Proses Perhitungan} Nilai fuzzy

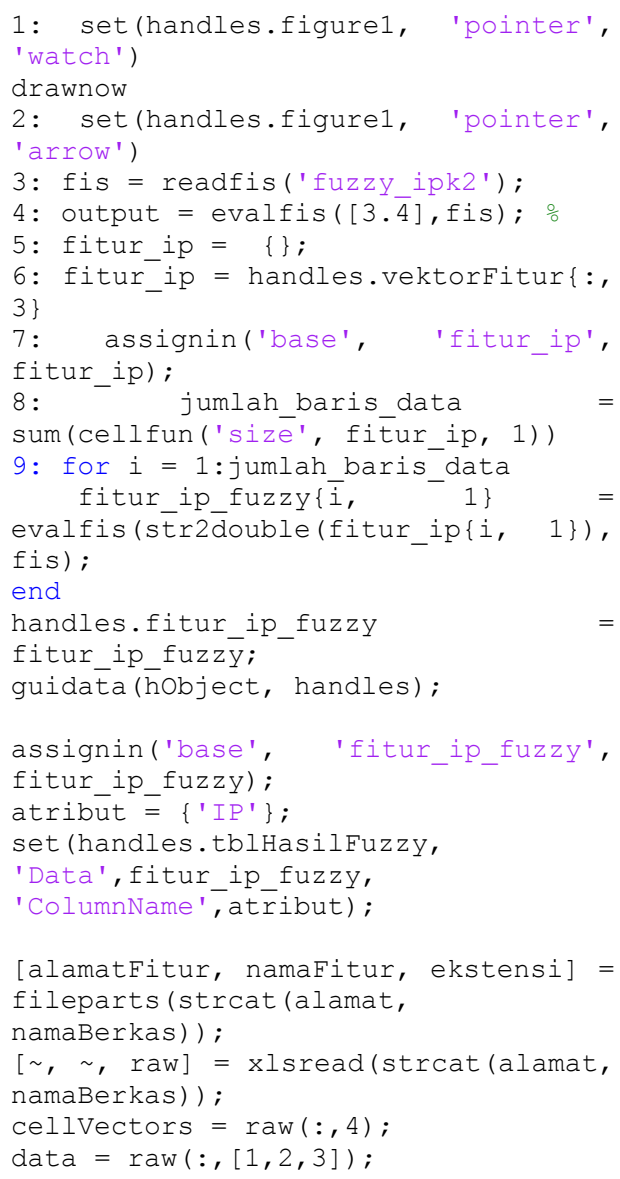

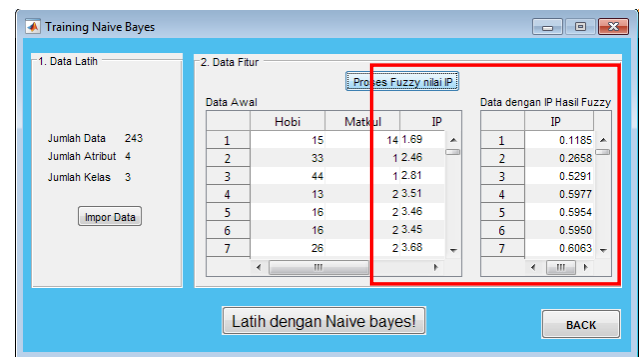

\section{Gambar 4.4 Hasil Perhitungan Nilai Fuzzy}

Proses pengolahan ipk menggunakan fuzzy adalah dari data awal yang telah diimport kedalam table kemudian dilakukan perhitungan menggunkan program dan menghasilkan nilai baru seperti ditampilkan pada form data IP hasil Fuzzy, fitur baru ini yang akan digunakan untuk prose data training menggantikan ipk yang lama, selanjutnya untuk proses training dengan melakukan pilih tombol latih dengan naive bayes. Hasilnya seperti gambar 4.5 berikut ini sedangkan untuk segmen program seperti pada segmen 4.2 Prose naive bayes\

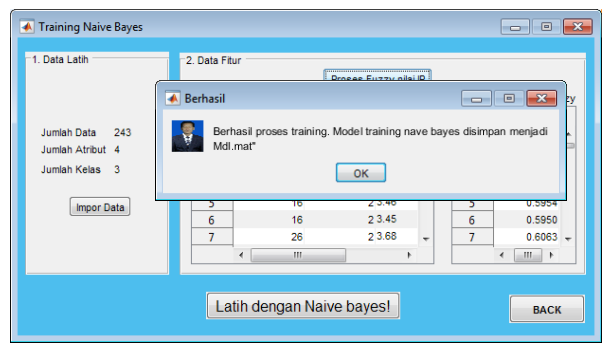

Gambar 4.5 Proses Training Naive bayes

Jika proses training berhasil dilakukan pada applikasi ini maka akan muncul pesan berhasil seperti diatas, hasil dari proses training akan disimpan kedalam file MDI.mat

\section{Segmen 4.2 Proses Training Naive Bayes}

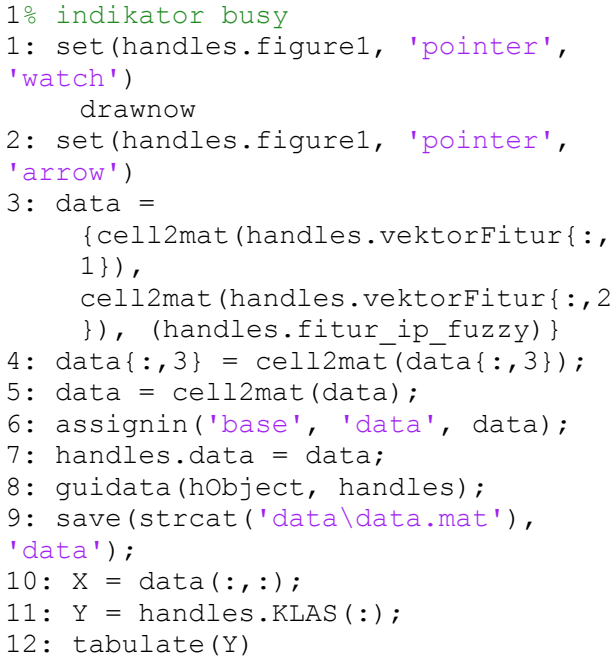




\section{Segmen 4.2 Lanjutan Proses Training Naive Bayes}

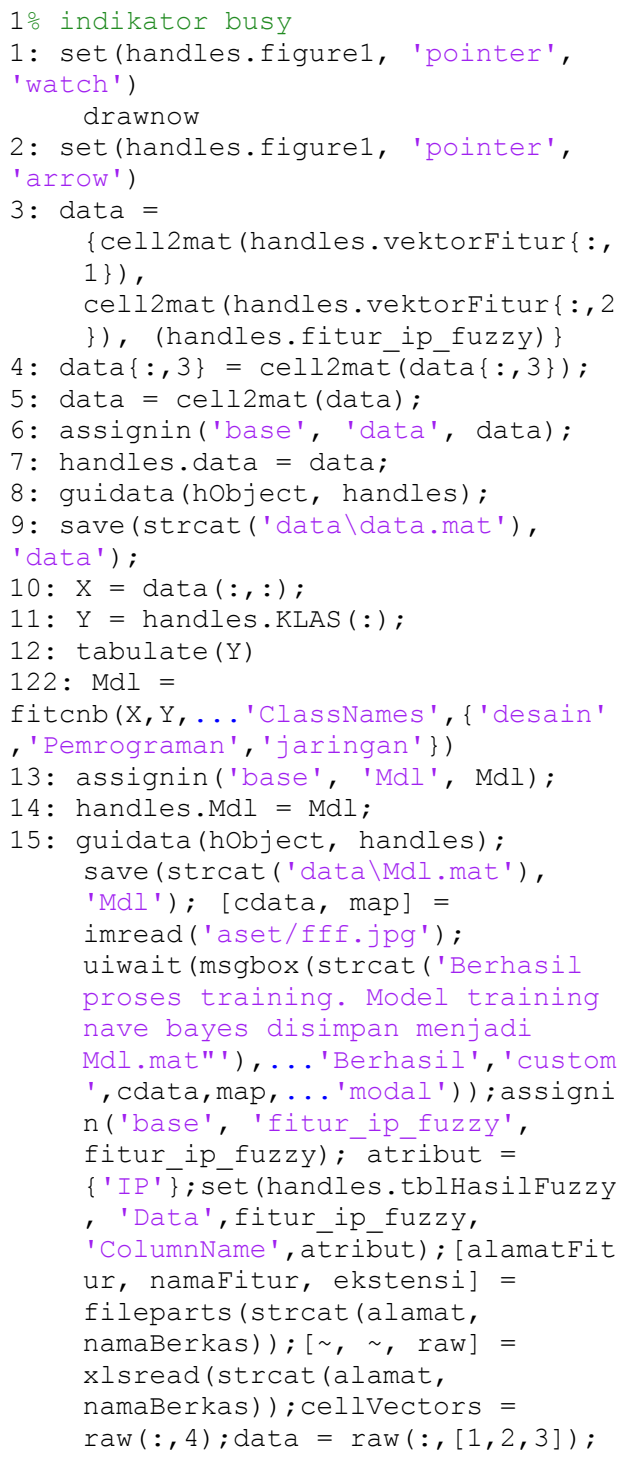

\subsection{Menu Testing}

Pada gambar 4.6 berikut ini akan dilakukan proses testing, Pada proses testing, performa algoritma akan diuji menggunakan testing set, dimana testing set dan training set merupakan data yang berbeda

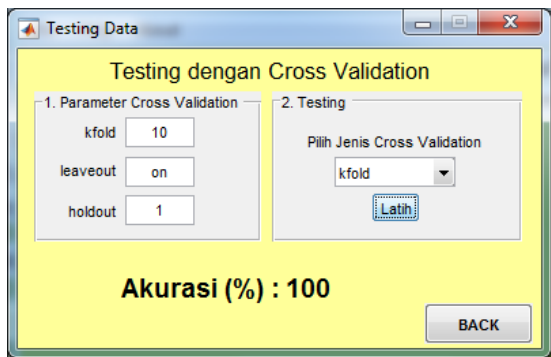

Gambar 4.6 Proses Testing

Proses tetsing adalah langkah pertama menentukan parameter cross validasi kemudian memberikan nilai besaran validasi setelah itu menentukan pilihan pada testing kemudian menekan tombol latih untuk melakukan validasi data dengan menggunakan data hasil training di awal.adapun segment program tersebut diatas seperti pada segmen 4.3 berikut ini

\section{Segmen 4.3 Proses Testing}

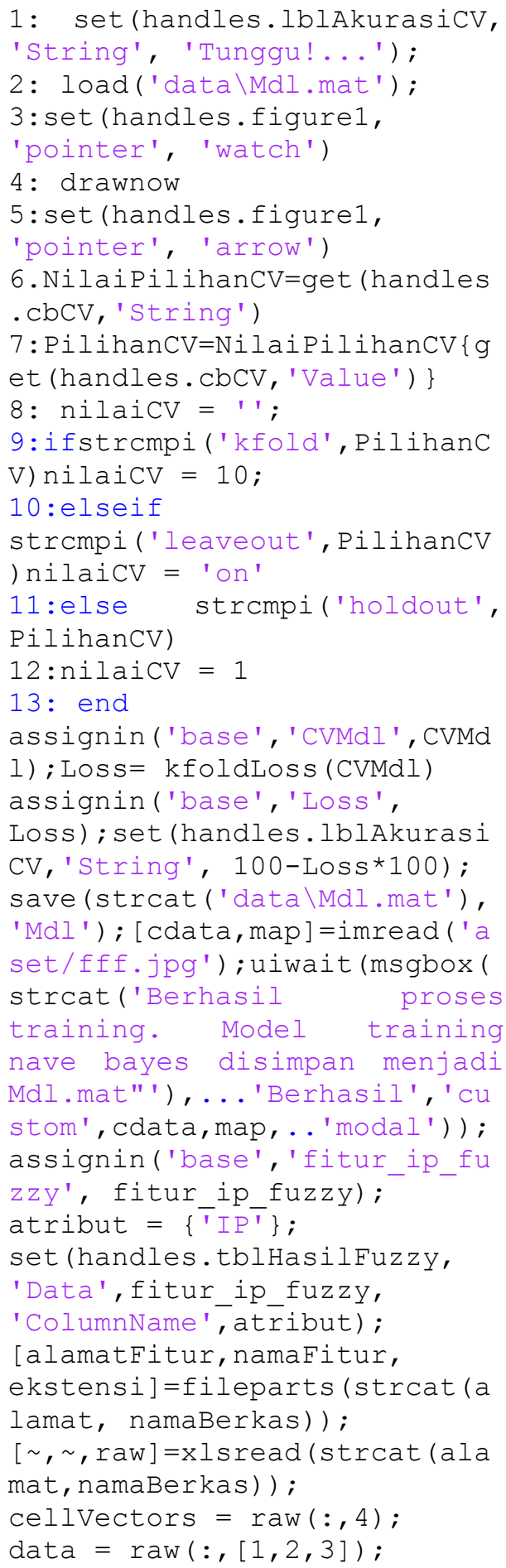


Dari analisa dan uji coba diatas maka dalam penelitian ini dapat disimpulkan sebagai berikut :

1. Aplikasi yang dibuat pada penelitian ini adalah membuat progam aplikasi klasifikasi bidang minat dengan menggunakan program matlab dan Algoritma Fuzzy Naive Bayes menghasilkan akurasi 100\% dengan errored $0 \%$ dari 243 data yang olah pada proses training.

2. algoritma fuzzy digunakan untuk konversi variabel ke dalam bentuk kategori dan algoritma naive bayes digunakan untuk menentukan pemilihan bidang minat

\section{PUSTAKA}

Dina Yulina Heriyani,Agus Sidiq Purnomo (2018).Rekomendasi Pemilihan Jurusan SMK Menggunakan Inferensi Fuzzy (Sugeno).

Teddy Pratama, Yulmainis,Implementasi Algoritma Naive Bayes Dalam Menentukan Konsentrasi Skripsi Dan Rekomendasi Bahasa Pemrograman .

Nur Nafi'iyah, Chastine Fatichah. (2018). Metode Fuzzy ID3 untuk Klasifikasi Bentuk Wajah Manusia Menggunakan Dental Panoramic.

Nur Nafi'iyah, Siti Mujilahwati. (2018, Agustus). Analisi Algoritma Backpropagation dan Naive Bayes dalamdentifikasi Jenis Kelamin Manusia Berdasarkan Foto Panoramik Gigi.

Anief Fauzan Rozi, Agus Sidiq Purnomo (2017) .Rekomendasi Pemilihan Minat Studi Menggunakan Metode Mamdani.

Darmawan, R. (2017). Perancangan Implementasi Sistem Pendukung Keputusan Penentuan Dosen Pembimbing Seminar Proposal Menggunakan Metode Naive Bayes.

Hartatik, (2017). Klasifikasi konsentrasi penjurusan mahasiswa universitas amikom Yogyakarta.

Eza Budi Perkasa (2017), Logika Fuzzy Untuk Penentuan Peminatan Pada SMAN 1 Pangkalpinang.

Basri, Muhammad Assidiq (2017) Klasifikasi Data pada Sistem Penjurusan dengan Preferensi Standar Simple Additive Weighting (PS-SAW) .

Husni Naparin, (2016).Klasifikasi Peminatan Siswa Sma Menggunakan Metode Naive Bayes. 